\title{
BMJ Open Changing relationships: how does patient involvement transform professional identity? An ethnographic study
}

\author{
Marie-Pierre Codsi (D , ${ }^{1}$ Philippe Karazivan, ${ }^{1,2}$ Ghislaine Rouly, ${ }^{2}$ Marie Leclaire, ${ }^{1}$ \\ Antoine Boivin ${ }^{1,2}$
}

To cite: Codsi M-P, Karazivan P, Rouly G, et al. Changing relationships: how does patient involvement transform professional identity? An ethnographic study. BMJ Open 2021;11:e045520. doi:10.1136/ bmjopen-2020-045520

- Prepublication history for this paper is available online. To view these files, please visit the journal online (http://dx.doi org/10.1136/bmjopen-2020045520).

Received 05 0ctober 2020 Accepted 15 June 2021
Check for updates

(c) Author(s) (or their employer(s)) 2021. Re-use permitted under CC BY-NC. No commercial re-use. See rights and permissions. Published by BMJ.

${ }^{1}$ Department of Family Medicine, University of Montreal Faculty of Medicine, Montreal, Quebec, Canada

${ }^{2}$ Center of Excellence for Partnership with Patients and the Public, CHUM, Montreal, Quebec, Canada

Correspondence to Dr Marie-Pierre Codsi; marie-pierre.codsi@umontreal. ca

\section{ABSTRACT}

Objectives To understand identity tensions experienced by health professionals when patient partners join a quality improvement committee.

Design Qualitative ethnographic study based on participatory observation.

Setting An interdisciplinary quality improvement committee of a Canadian urban academic family medicine clinic with little previous experience in patient partnership. Participants Two patient partners, seven health professionals (two family physicians, two residents, one pharmacist, one nurse clinician and one nurse practitioner) and three members of the administrative team.

Data collection Data collection included compiled participatory observations, logbook notes and semistructured interviews, collected between the summer of 2017 to the summer of 2019.

Data analysis Ghadiri's identity threats theoretical framework was used to analyse qualitative material and to develop conceptualising categories, using QDA Miner software (V.5.0)

Results All professionals with a clinical care role and patient partners $(n=9)$ accepted to participate in the ethnographic study and semi-structured interviews (RR=100\%). Transforming the 'caregiver-patient' relationship into a 'colleague-colleague' relationship generated identity upheavals among professionals. Identity tensions included competing ideals of the 'good professional', challenges to the impermeability of the patient and professional categories, the interweaving of symbols associated with one or the other of these identities, and the inner balance between the roles of caregiver and colleague.

Conclusion This research provides a new perspective on understanding how working in partnership with patients transform health professionals' identity. When they are called to work with patients outside of a simple therapeutic relationship, health professionals may feel tensions between their identity as caregivers and their identity as colleague. This allows us to better understand some underlying tensions elicited by the arrival of different patient engagement initiatives (eg, professionals' resistance to working with patients, patients' status and remuneration, professionals' concerns toward patient 'representativeness'). Partnership with patients imply the construction of a new relational framework, flexible and dynamic, that takes into account this coexistence of identities.

\section{Strengths and limitations of this study}

- The methodology used (participatory ethnographic approach) was carried out over a period of more than 2 years, enriched the understanding of the phenomenon under study, allowing researchers to have access to informal discussions that helped uncover identity tensions that were not obvious in individuals' interviews.

- The important contribution of this methodology is to import an identity analytical framework from the business literature to help understand challenges of patient partnership implementation and to provide an interpretive reading that is different from the current literature, shedding light on issues frequently encountered in the field (eg, professionals' resistance to working with patients, patients' status and remuneration, professionals' concerns toward patient 'representativeness').

- Because the ethnographic approach was used in a single setting, the analysis focused more on professionals' individual identity, whereas a multiple case study in several types of professional environments would have made it possible to contrast the impact of relational changes on professionals' collective identity.

- To uncover as many potential issues as possible, we chose to study a team undergoing its first experience of working in partnership with patients.

- Working with a team that was relatively new to the subject was potentially more conducive to exposing the identity shock that resulted when relationships were transformed from caregiver-patient to colleague-colleague.

It is in these roles that we know each other; it is in these roles that we know ourselves. ${ }^{1}$

\section{INTRODUCTION}

Over the past decades there have been growing calls for greater patient and public involvement (PPI) in healthcare systems around the world. ${ }^{2-5}$ The PPI movement is today one of the main vectors for creating 
different initiatives and new models of care ${ }^{6-11}$ Despite the problematic context of the COVID-19 pandemic, many new initiatives are now recruiting patients to help rethink policies ${ }^{1213}$ and medical education. ${ }^{14}$

Studies conducted in the wake of PPI initiatives have identified the emergence of several barriers and resistances. Questions have arisen about patients' status within teams, ${ }^{1516}$ the legitimacy of their knowledge and contribution, ${ }^{16-18}$ the impacts on care quality ${ }^{3} 19$ and the new power relationships being formed within healthcare teams and the health system. ${ }^{20}{ }^{21}$ While some have attempted to understand the issues raised by such experiences, ${ }^{1721-23}$ no study, to our knowledge, has focused on understanding the potential identity tensions for professionals when they are called to interact with patients outside of a simple therapeutic relationship. This is important as many new care models posit that patients should be integrated as partners to contribute to quality improvement, medical research, teaching programmes and health institution governance. ${ }^{819222425}$ These initiatives seek to involve them in all stages of decision-making. ${ }^{26}$ However, professionals and patients' identities are historically based on a caregiving relationship in which professionals are responsible for caring for the patient. ${ }^{27}$ Therefore, for health professionals, working with patients not as caregiver, but as partner, directly affects the traditional way of doing and viewing oneself, as health professional. ${ }^{28}$ This could explain some barriers and resistances experienced on the field.

The present study thus examined identity changes that can arise when patients and health professionals begin working together as partners. Understanding success or failure of organisational change from an identity perspective has so far mainly been used in the business literature. ${ }^{29-33}$ Uncovering these tensions and how these tensions are experienced by health professionals could bring a deeper understanding of professional barriers and resistance to PPI, ${ }^{17}$ and potentially reorient implementation strategies.

\section{METHODOLOGY Objective}

The objective was to understand the identity tensions experienced by health professionals when partnering with patients on a quality improvement committee.

\section{Design}

The study followed a participatory ethnographic design. $^{34-38}$ In this ethnographic approach, M-PC (family medicine resident), PK (family physician) and GR (patient partner) acted as participant observers, ${ }^{39} 40$ participating both as members of the quality improvement committee and members of the research team. Two additional investigators ( $\mathrm{AB}$ and $\mathrm{ML}$ ) were non-participants.

\section{Conceptual model}

This study was based on the conceptual model of identity threats developed by Ghadiri (2014). Sacha Ghadiri's work was particularly interesting for our research question as it proposed a model to understand resistance to change resulting specifically from identity tensions.

Identity answers the fundamental question, "who am I?. ${ }^{41}$ Identity changes and is transformed in response to several factors: personal characteristics, context, sense of belonging, relationships with others and how others view us. ${ }^{41}$ Individuals or social groups are strongly attached to their identity. Change, however small it may seem, may threaten the identity of an individual or group. ${ }^{31}{ }^{33}$ If that identity is threatened, individuals and groups will defend it strongly, whether consciously or not.

To facilitate the implementation of any change in an organisation, Ghadiri proposes to undertake an identity analysis of the issues involved. To do so, he suggests focusing particularly on certain manifestations of identity that he calls 'identity markers': stories, ideals, balances, categorisations and symbols. These markers are manifestations of identity that are more susceptible to tension when change occurs and can generate resistance when they are shaken up.

Stories are ways in which the identity of the group or individual is told. Individuals may be threatened when, for example, a change prevents them from identifying with a story that was particularly dear to them. Ideals are conceptions or aspirations that we wish to achieve. A change can be experienced as a threat if it poses an obstacle to attaining this ideal. An individual or group may have several concurrent identities, which coexist in a sometimes delicate balance. A change can be experienced as a threat if it disrupts this balance. Categorisations are labels explicitly or implicitly associated with an individual or group of individuals. They are manifested, among other things, by the ways in which individuals are valued or treated according to the category to which they belong. Finally, symbols can be manifested in elements such as attire, access to premises and so on. Identity can be threatened, 'whether by eliminating symbols, disrupting them, eroding them, replacing them, denying access or making their expression difficult...' (Ghadiri, p43) ${ }^{30}$

\section{Study context}

In 2017, a family medicine clinic created an interdisciplinary quality improvement committee. The clinic was a large academic primary care group practice located in Montreal, caring for approximately 13500 patients in collaboration with 80 health professionals. This clinic has a longstanding tradition of interprofessional care, but no previous experience with patient involvement in quality improvement. The quality improvement committee functioned from summer 2017 to summer 2019, a meeting lasting 2 hours approximately each 2 months. Its mandate was to optimise the management of laboratory results at the clinic. Patient partners (PP) involved on the committee were recruited by the clinic staff during the 
fall of 2017 using the Centre of Excellence for Patient and Public Partnership recruitment methodology. ${ }^{42}$

\section{Study participants}

The committee consisted of two PPs, seven health professionals (two family physicians, two family medicine residents, one pharmacist, one nurse clinician and one specialised nurse practitioner), one secretary, one receptionist and one manager. All members of the committee were invited to participate in the ethnographic process. Of these members, only health professionals and PPs were invited to participate in individual interviews, as our project focused on health professionals' identities with a clinical care role. Three members of the committee were also members of the research team (M-PC as a resident in family medicine, PK as a family physician, and GR as a PP).

\section{Data collection}

Data collection began in 2017, when the committee was officially created, and ended in winter 2019. It consisted of participatory observations in a logbook, semi-structured interviews and the principal investigator's personal diary. Participatory observations included involvement in the recruitment of $\mathrm{PP}$ and attendance of all committee meetings by M-PC, PK and GR. Participatory observations captured summaries of participants' interventions during the meetings and the decisions taken by the committee. The participatory observations also included a summary of all informal discussions among participants and the research team concerning the implication of a PP in the committee. First, after each meeting, participants were met informally over the following days by one of the research team members to gather feedback on the committee. A summary of these informal 'corridor discussions' was collated by M-PC in the logbook. Also, M-PC, PK and GR met one or two times a month to debrief between meetings and to collect their different observations from their different perspectives. M-PC took notes of all these different debriefs in the logbook.

Semi-structured interviews, lasting between 90 and $120 \mathrm{~min}$, were conducted by M-PC with professionals and PPs around the end of the committee's mandate. PK and GR were also officially interviewed by M-PC as participants in the committee. The questions in the interview guide were developed on the basis of Ghadiri's identity markers (eg:-Did you feel any tensions or conflicts during the process?-What is an ideal PP? -What is the role of the PP?-What is your role in the committee?). Ghadiri's conceptual framework was used during all the data collection process to build our interview guide and to help us guide our field observations.

The principal investigator M-PC was herself interviewed by ML (who was not present during meetings) using clarifying interview techniques. A personal diary also testified to the principal investigator's impressions and feelings as a family medicine resident throughout the process. These data were analysed to ensure the plausibility of the process and of the data collection, as described in participatory ethnography methodologies. ${ }^{34} 43-46$

\section{Data analysis}

Qualitative ethnographic analysis by conceptualising categories as described by Paille ${ }^{47}$ was used. Data were compiled using QDA Miner software (V.5.0). Analysis was begun alongside data collection and used iteratively to enhance the data collection itself. All data collected from participatory observations, logbook notes and semistructured interviews was coded and grouped around major emerging categories by the principal investigator (M-PC) and by ML as a second coder to enhance trustworthiness. The analysis was then entirely refined by $\mathrm{AB}$ and PK. It was then finally refined again by all the research team (M-PC, PK, GR, ML and AB). The socioprofessional background of every researcher was different (resident in family medicine, psychologist, physicians and patient). The research team therefore discussed and compared each other's ideas and interpretations until a consensus was obtained among all researchers, giving the opportunity to enrich the final analysis.

\section{Patient and public involvement}

One patient partner (GR) was involved at several stages of the study, at the same level of the others co-researchers (PK, ML and $\mathrm{AB}$ ). All the project's important decisions were discussed and decided in partnership with the patient. All the co-researchers met on a regular basis for the duration of the project. GR was involved in the discussion and writing of the study protocol, the ethics procedures, the data collection and analysis and the present article's manuscript. GR contributed to the dissemination plan through being a co-presenter for congress abstract presentations and through the coauthoring of this present article.

\section{RESULTS}

\section{Participants}

All participants $(\mathrm{n}=12)$ agreed to contribute to the participatory ethnographic process. Of these participants, all health professionals and PPs $(n=9)$ agreed to participate to individual interviews $(\mathrm{RR}=100 \%)$.

\section{Identity markers}

\section{Stories: pioneers threatened in their image of excellence}

In interviews, professionals reported a shared collective story that their clinic had always been known for its strong focus on innovation and quality of care. They all thought that this new experience of partnering with patients was thus in line with the clinic's tradition, being rooted in a collective identity of innovation. All concurred that patients had been integrated as full members of the team during the committee's work. In their initial comments, no conflicts or tensions were reported: a committee in which their professionals' collective identity story of innovators was enhanced and did not seem to have been disrupted 
Table 1 Identity markers: citations and observations collected

\section{Identity markers Citations and observations collected}

\begin{tabular}{|c|c|}
\hline 1. Stories & $\begin{array}{l}\text { a. Citation: "I see everyone is comfortable. I don't feel that... there's any discomfort. I find there's not } \\
\text { really any... people aren't holding back, because I know them, and what they're saying, it's what they } \\
\text { say in general in their everyday life. It's in the spirit of the times... It wasn't something that... we were } \\
\text { against. No one was against that."-Professional A } \\
\text { b. Citation: "Well, I don't think anyone said.... It's not conscious, but to a certain extent, we're afraid of } \\
\text { each other."-Professional M } \\
\text { c. Citation: "When we explained our internal problems [in front of patients as partner], it was a little } \\
\text { embarrassing, because normally we're supposed to be perfect. That's how it is, in fact, it's like a } \\
\text { perfect image. Then, there, we took them behind the scenes.... So then it was a bit embarrassing [to } \\
\text { admit] "we're not perfect, you know."'-Professional S }\end{array}$ \\
\hline
\end{tabular}

2. Ideals

Citation: "This is a departmental priority. Besides that, it's become a priority for the [health authority], it's become a priority for everyone.... They all feel there's a lot of pressure for us to be endorsed by the "patient partner" brand."-Professional P

3. Balance a. Citation: "We may well be colleagues, but still, they're patients, and I always feel the... urge to
provide care, and then we said: 'we want them to be happy, and do well in there, and feel valued."”-
Professional P
b. Citation: "I'd say that, when it's a colleague, I feel more able to confront him.... But when it's a
patient... you have to wear... in my thinking, anyway... because he represents the good folks, you
have to treat them with kid gloves more often."-Professional A
c. Citation: "(...) At the same time, I see it as a bias, because we're working with two patients who are
used to work on committees." - Professional S

4. Categorisation

a. Citation: "The most important thing for me is to clarify the role, what we're doing around the table, and why we're all here."-Professional $P$

b. Citation: "Then, because everyone is also a patient... I think that's why... but our patient is more of a patient than we are, his role is to bring that... You know, us, it's not really our role to bring our role as a patient there, either..."

c. Observations: certain situations helped increase the PP's legitimacy and clarify the boundaries between PP's and professional's identity.

I. when PP surprised the team with information or suggestions based on their own care experience that none of the professionals had previously experienced or considered.

II. when PP contradicted a preconceived notion held by professionals regarding patients' experience. III. when PP were able to touch team members emotionally with their personal experience of care.

5. Symbols a. Citation: "If I were asked to be a patient partner, l'd like to be paid. Just to say you have a value. It's
not just volunteering. It's crazy, because we have a system [in which] basically, after all... it seems that
your salary is your worth." - Professional A

PP, patient partners.

in any way (cf table 1.1.a). However, when probed deeper, particularly in corridor conversations, professionals indicated that the PP's inclusion was not accomplished without fear or apprehension (cf table 1.1.b).

During the field observations, there was a level of anxiety felt by professionals during the first interactions with PP. When certain quality problems were discussed, professionals were particularly attentive to the PP's reactions, as these discussions were threatening professionals' collective story of clinical excellence (cf table 1.1.c). If PP expressed surprise or disappointment, some professionals quickly sought to minimise the impact of the problem or defend the professionals' reality.

The way in which the professionals spontaneously described their experience was in line with their collective identity story of innovators, working in a pioneer primary care practice. However, corridor discussions revealed a fear that PP's presence in the 'backstage' of professional practice could uncover 'imperfections' or 'shortcomings' that would undermine professionals' identity story of excellence.

\section{Ideals: partnership with patients, a new professional ideal}

All professionals concurred that working in partnership is the new 'right thing to do' (cf table 1.2). The professionals therefore worked to ensure the success of the experience to be 'good' partners. Professionals mentioned that their relationship with patients should not be hierarchical, but rather built on reciprocity and transparency. Disagreements should be expressed freely and without filters. Our field observations showed that professionals and patients working together felt a need 
Table 2 Characteristics of each relational model as perceived by professionals

\section{Caregiver-patient relationship}

\begin{tabular}{lll} 
& Caregiver - patient relationship & Colleague-colleague relationship \\
\hline Identity of physician & Caregiver & Colleague \\
Identity of patient & Recipient of care & Colleague \\
Relational distance & Asymmetrical & Symmetrical \\
Relational objective & Care & Work
\end{tabular}

(for the professional) to show stronger connections between each other than what usually occurs in clinical care. For example, the use of informal terms of address (eg, using first names), the sharing of personal stories and demonstrations of camaraderie between patients and professionals were methods routinely used to demonstrate that they were not in a caregiver relationship, and to illustrate that the professionals were successful in embodying this perception of the new non-hierarchical relationship ideal.

Even as professionals strive to attain the ideal of partnership, they also hold another pre-existing, strong and deeply entrenched relational ideal: that of the 'good caregiver' looking after patients. Particularly present among the physicians in the committee, this ideal is embodied in the image of the caring doctor responsible for his or her patients' well-being. One of the most important objectives for caregivers is to protect the patients' trust in their professionals. Professionals will oppose anything that could jeopardise the trust needed for the care relationship. They are afraid to become too familiar or to reveal flaws or imperfection and believe that, in order to prevent this, they must maintain a professional 'healthy distance'. This identity ideal is also reinforced by the code of ethics to which professionals adhere. ${ }^{48}$ Our results, summarised in table 2, showed that these two relational models are based on identity ideals with potentially conflicting requirements.

\section{Balance: identity tensions between patients as colleagues and people being cared for}

Data suggests that, in the committee, professionals had two competing identities (colleague and caregiver), with which they had to deal with simultaneously. Even as the professionals aimed to consider PP as colleagues, interviews showed they also viewed them as innocent, vulnerable beings that they felt responsible for (cf table 1.3.a).

After all, professionals consider that the PP who joins the committee is still a patient of the clinic and, as such, a recipient of care. Consequently, professionals find confronting the PP very uncomfortable, at least openly (cf table 1.3.b).

If professionals see PP as full members of the team, they will distance them from the 'ordinary' patient and consider that they are all part of the same "professional family'. However, this was also seen as a negative element by the professionals, since the PP would no longer be able to adequately embody the identity of an ordinary patient and would be too far removed from the 'real world' (cf table 1.3.c). This issue was repeatedly expressed by professionals as a concern regarding the insufficient 'representativeness' of the PP.

Corridor conversations and direct observations also revealed another identity tension among professionals regarding the balance between their identity as colleague and as caregiver: if a PP asked for a medically-related personal service (eg, help getting an appointment with a doctor, medical advice or a referral), the professional felt uncomfortable and hesitated about the correct way to respond to this request (as a doctor? A colleague? A friend?).

\section{Categorisation: the newcomer, boundaries to be defined}

The data shows that the boundaries between PP and professional's identity are sometimes blurred and that, for professionals, the definition of the PP's role remains ambiguous. This complicated the way professionals viewed the PP's category (cf table 1.4.a) and, as such, the proper way to work with them. Some professionals noted that if the discussion touched them personally, they tended to recall their own experiences as a patient. Thus, they considered that the 'patient' label could be applied to them as well. Professionals therefore expected PP to bring to the table knowledge that was different from that of other team members (cf table 1.4.b).

Moreover, we observed that certain situations helped increase the PP's legitimacy and clarify the boundaries between PP's and professional's identity (cf table 1.4.c). Such cases help the professional establish an identity boundary that categorises the PP as 'colleagues with a different expertise'.

\section{Symbols: remuneration, as a symbolic identity issue}

Several identity symbols were challenged by PP involvement in the committee. Notably, PP's remuneration raised not only financial questions, but also questions around roles and status. Beyond its practical implications (Should they be paid? How much? Who should pay?), remuneration debates crystalised identity questions (eg, Did a salary imply employee status? How does it distinguish patient partners with professionals' roles?). Most of the professionals concluded that, as they all shared the same identity within the committee, they should all be paid. However, when questioned on the salary PPs should obtain, professionals showed discomfort. Their opinions 
were divided because different professions were paid a different hourly rate for their participation. Some of them expressed their beliefs that PPs should not be paid more than the lowest paid participant around the table. At the same time, they expressed concern about the fact that PPs should not be the lowest paid participant since they felt someone's value was somewhat reflected in their salary (cf table 1.5.a).

Other symbols have raised questions rooted in the professionals' perception of the PP's dual identity as colleagues and users of care. For example, granting PP clinic access card and the nature of their confidentiality obligations were the subject of several discussions in the committee.

\section{DISCUSSION}

This study reports and interprets how working with patients is a new way of entering into relationships and how this transforms the identity of professionals. Even if, in this study, all participants agreed that the experience was a success in terms of partnership with patients, transforming the 'caregiver-patient' relationship into a 'colleague-colleague' relationship generated identity upheavals among the professionals, relating to the 'good professional' ideal, the impermeability of the patient and professional categories, the interweaving of the symbols associated with these identities and the inner balance between the roles of carer and colleague. Professionals struggle with this dual identity and transfer this ambiguity to their perception of the patient's identity as a 'real patient' or not. This could explain some professionals' perception of PP identity mentioned in the literature as ambiguous and poorly defined. ${ }^{1549}$

Given the coexistence of multiple identities, striking a balance between them brings many challenges for the professional. While balancing identities is complex, professionals cannot relinquish either of their identity ideals without consequence. On one hand, if professionals perceive the patient as sufficiently distanced from this image of care receiver, they will feel comfortable to work in a colleague-colleague relationship. The energy will be focused more on productivity than on creating a positive relational experience. On the other hand, if the professional sees the PP as too far removed from what is considered an 'ordinary patient' identity, the professional will consider the person's presence to be less legitimate, even irrelevant. This is mainly because the professional grants the person legitimacy on the basis of a patient identity, while giving the person access to real relational reciprocity on the basis of a coworker identity.

The important contribution of this study is to import an identity analytical framework to help understand challenges of PP implementation. This provides an interpretive reading that is original and different from the current literature, shedding light on certain issues frequently encountered in the field (eg, professionals' resistance to working with patients, merely symbolic involvement of patients, remuneration, patients' status and unequal power relationships between professionals and PP, professionals' concerns toward patient 'representativeness') ${ }^{3}$ 15-18 2122 49-52 that could be indicative of underlying identity tensions between patients and health professionals.

\section{Strengths, limitations, and future research}

The methodology used (participatory ethnographic approach) carried out over a period of more than 2 years, enriched the understanding of the phenomenon under study, allowing researchers to have access to informal corridor discussions that helped uncover identity tensions that were not obvious in formal interviews. This methodology follows in the footsteps of recent literature striving for the study of complexity in health services. ${ }^{53-56}$

Observations were conducted by multiple observers (two family doctors and one patient) on the same meetings which is, in our opinion, a strength for the analysis process. However, because the ethnographic approach was used in a single setting, the analysis focused more on one primary care team identity, whereas a multiple case study in several types of professional environments would have made it possible to contrast the impact of relational changes on professionals' collective identity. Also, to uncover as many potential issues as possible, we chose to study a team undergoing its first experience of working in partnership. It would be interesting to see whether similar results would emerge with a more experienced team, in which the balance and tensions between different identities might have already stabilised to some extent over time. On the other hand, working with a team that was relatively new to the subject was potentially more conducive to exposing the identity shock that resulted when relationships were transformed from caregiver-patient to colleague-colleague. Future research is also needed to better understand identity issues experienced by patient partners.

Finally, some might conclude that this research calls for ways to help professionals minimise these identity tensions. However, it is important to consider whether, in essence, creating identity tensions is not the very strength of working in partnership with patients. This would perhaps need to be questioned yet again if ambiguity and relational discomfort were to disappear and be replaced by a relationship that is too 'complacent'.

\section{CONCLUSION}

This research provides a new perspective on understanding how working in partnership with patients transform health professionals' identity. When they are called to work with patients outside of a simple therapeutic relationship, health professionals may feel tensions between their identity as caregivers and their identity as colleague. This allows us to better understand some underlying tensions elicited by the arrival of different patient engagement initiatives (eg, professionals' resistance to working 
with patients, patients' status and remuneration, professionals' concerns toward patient 'representativeness'). Partnership with patients imply the construction of a new relational framework, flexible and dynamic, that takes into account this coexistence of identities.

Contributors This study was conducted in the context of primary author's Master degree (M-PC). M-PC, PK, GR and AB designed and conducted the study. The data collection was done by M-PC. The coding was done by M-PC and ML. The data analysis was done by all coauthors (M-PC, PK, GR, AB and ML). M-PC prepared the manuscript draft with important intellectual input from all the other coauthors. All authors approved the final manuscript and the revised version.

Funding This project received the Patient's Medical Home 60/20 Caring and Compassion grant (4000\$) and the University of Montreal Interfaculty Operational Committee grant $(7500 \$)$.

Competing interests All authors have completed the ICMJE uniform disclosure form at www.icmje.org/coi disclosure.pdf and declare: M-PC, GR, PK and AB are part of the CEPPP team (Centre of Excellence for Partnership with Patients and the Public). AB and PK are both co-directors of the Centre of Excellence for Partnership with Patients and the Public in Montreal; $A B$ is the chairholder of the Canada Research Chair in Patient and Public Partnership. M-PC affirms that the researchers work was totally independent from funders.

Patient and public involvement Patients and/or the public were involved in the design, or conduct, or reporting, or dissemination plans of this research. Refer to the Methods section for further details.

\section{Patient consent for publication Not required}

Ethics approval The project was approved by the ethics committee for research on addiction, social inequalities and public health of the CIUSSS Centre-Sud-deI'Île-de-Montréal (DIS-1718-38). All information was anonymised to protect the identity of the various participants.

Provenance and peer review Not commissioned; externally peer reviewed.

Data availability statement Data are available upon reasonable request. Data are available upon reasonable request (Individual participant data that underlie the results reported in this article, after de-identification, study protocol, informed Consent Form, Analytic Code).

Open access This is an open access article distributed in accordance with the Creative Commons Attribution Non Commercial (CC BY-NC 4.0) license, which permits others to distribute, remix, adapt, build upon this work non-commercially, and license their derivative works on different terms, provided the original work is properly cited, appropriate credit is given, any changes made indicated, and the use is non-commercial. See: http://creativecommons.org/licenses/by-nc/4.0/.

Author note ${ }^{* \star \star}$ This article follows the guidelines by the European Medical Writers' Association on the role of professional medical writers. ${ }^{* \star \star}$

ORCID iD

Marie-Pierre Codsi http://orcid.org/0000-0002-1720-3416

\section{REFERENCES}

1 Park RE. Race and culture. Free Press, 1950: 403

2 Fleurence R, Selby JV, Odom-Walker K, et al. How the patientcentered outcomes research Institute is engaging patients and others in shaping its research agenda. Health Aff 2013;32:393-400.

3 Bombard Y, Baker GR, Orlando E, et al. Engaging patients to improve quality of care: a systematic review. Implement Sci 2018;13:98.

4 Russell J, Greenhalgh T, Taylor M. Patient and public involvement in NIHR research 2006-2019: policy intentions, progress and themes, 2019.

5 Clavel N, Pomey M-P, Ghadiri DPS. Partnering with patients in quality improvement: towards renewed practices for healthcare organization managers? BMC Health Serv Res 2019;19:815.

6 Coulter A. Paternalism or partnership? patients have grown up-and there's no going back. BMJ 1999;319:719-20.

7 Richards T. Tessa Richards: transforming healthcare-one flower at a time. Thebmjopinion. BMJ 2019.

8 Karazivan P, Dumez V, Flora L, et al. The patient-as-partner approach in health care: a conceptual framework for a necessary transition. Acad Med 2015;90:437-41.
9 Barry MJ, Edgman-Levitan S. Shared decision making--pinnacle of patient-centered care. N Engl J Med 2012;366:780-1.

10 Bodenheimer T, Lorig K, Holman $\mathrm{H}$, et al. Patient self-management of chronic disease in primary care. JAMA 2002;288:2469-75.

11 Tattersall RL. The expert patient: a new approach to chronic disease management for the twenty-first century. Clin Med 2002;2:227-9.

12 Boivin A, Penafiel M, Rouly G. TheBMJopinion [Internet]. BMJ, editor 2020. Available: https://blogs.bmj.com/bmj/2020/04/07/covid-19-apivotal-moment-in-community-care/

13 Quirion R. Création du Réseau québécois COVID. Gouvernement du Québec, 2020.

14 Jackson M, Descôteaux A, Nicaise L, et al. Former en ligne au recrutement de patients partenaires: l'apport des formations par concordance. Pédagogie Médicale 2020;21:101-6.

15 Barber R, Boote JD, Parry GD, et al. Can the impact of public involvement on research be evaluated? A mixed methods study. Health Expect 2012;15:229-41.

16 Lough S. Need to define patient engagement in research. CMAJ 2015;187:E385-6.

17 Staniszewska S, Mockford C, Gibson A, et al. Moving Forward: Understanding the Negative Experiences and Impacts of Patient and Public Involvement in Health Service Planning, Development, and Evaluation. In: Barnes M, Cotterell $\mathrm{P}$, eds. Critical perspectives on user involvement edn. Bristol: Policy, 2012: 129-41.

18 Domecq JP, Prutsky G, Elraiyah T, et al. Patient engagement in research: a systematic review. BMC Health Serv Res 2014;14:89.

19 Aubin D, Hebert M, Eurich D. The importance of measuring the impact of patient-oriented research. CMAJ 2019;191:E860-4.

20 Saraga M. Transparence, transfert et patient partenaire. PsychoOncologie 2018;12:24-8.

21 O'Shea A, Boaz AL, Chambers M. A hierarchy of power: the place of patient and public involvement in healthcare service development. Front Sociol 2019;4:38.

22 Montreuil M, Martineau JT, Racine E. Exploring Ethical Issues Related to Patient Engagement in Healthcare: Patient, Clinician and Researcher's Perspectives. J Bioeth Inq 2019;16:237-48.

23 Boivin A, Lehoux P, Burgers J, et al. What are the key ingredients for effective public involvement in health care improvement and policy decisions? A randomized trial process evaluation. Milbank $Q$ 2014;92:319-50.

24 Boivin A, Richards T, Forsythe L, et al. Evaluating patient and public involvement in research. BMJ 2018;363:k5147.

25 Aldcroft $A$. New requirements for patient and public involvement statements in BMJ open. BMJ Open 2018.

26 Carman KL, Dardess P, Maurer M, et al. Patient and family engagement: a framework for understanding the elements and developing interventions and policies. Health Aff 2013;32:223-31.

27 Parsons T. The sick role and the role of the physician reconsidered. Milbank Mem Fund Q Health Soc 1975;53:257-78.

28 Richards T. Patient leaders - healthcare's untapped workforce, 2017. TheBMJopinion. Available: https://blogs.bmj.com/bmj/2017/12/22/ tessa-richards-patient-leaders-healthcares-untapped-workforce/

29 Conroy SA, O'Leary-Kelly AM. Letting go and moving on: workrelated identity loss and recovery. Acad Manage Rev 2014;39:67-87.

30 Ghadiri DP. Quand le changement menace I'identité. Gestion 2014;39:38-47.

31 Branscombe NR, Ellemers N, Spears R, et al. The context and content of social identity threat. In: Social identity: context, commitment, content, 1999: 35-58.

32 Fiol CM, Pratt MG, O'Connor EJ. Managing intractable identity conflicts. Acad Manage Rev 2009;34:32-55.

33 Ford JD, Ford LW. Decoding resistance to change. Harv Bus Rev 2009;87:99-103.

34 Blomberg J, Karasti H. Positioning ethnography within participatory design. In: Routledge international Handbook of participatory design, 2012: 86-116.

35 Diaz F. L'observation participante comme outil de compréhension du champ de la sécurité. Récit d'un apprentissage de l'approche ethnographique pour tenter de rendre compte de la complexité du social. Champ pénal/Penal field 2005;2.

36 Gérin-Lajoie D. L'utilisation de l'ethnographie dans l'analyse du rapport l'identité. Éducation et sociétés 2006;1:73-87.

37 Lapassade G. L'observation participante. Revista Europeia de Etnografia da Educação 2001;1:9-26.

38 Mehan $\mathrm{H}$, Wood $\mathrm{H}$. The morality of ethnomethodology. Theory Soc 1975;2:509-30.

39 Gold RL. Roles in sociological field observations. Social Forces 1958;36:217-23.

40 Kawulich BB, ed. Participant observation as a data collection method. Forum qualitative sozialforschung/forum: Qualitative social research, 2005 
41 Goffman E, Kinm A. La mise en scène de la vie quotidienne: Minuit Paris, 1973.

42 DCPP. Guide de pratique: Recrutement des patients partenaires. Faculté de médecine: Université de Montréal, 2015.

43 Ellis C, Bochner A. Autoethnography, personal narrative, reflexivity: researcher as subject, 2000.

44 Rondeau K. L'autoethnographie: une quête de sens réflexive et conscientisée au cœur de la construction identitaire. Recherches qualitatives 2011;30:48-70.

45 Dubé G. L'autoethonographie, une méthode de recherche inclusive, 2016. Available: https://www uqar ca/uqar/universite/a-proposdeluqar/departements/psychosociologie et travail social/presencesvol9-2-dubelautoethnographie-une-methode-de-recherche-inclusive pdf

46 Chang $\mathrm{H}$. Individual and collaborative autoethnography as method. In: Handbook of autoethnography, 2013: 107-22.

47 Paillé P, Mucchielli A. L'analyse qualitative en sciences humaines et sociales. 4th édn. Armand Colin, 2016.

48 Collège des médecins du Québec. Code of ethics of physicians, 2019. Available: http://www.cmq.org/page/en/code-de-deontologiedes-medecins.aspx

49 Brett J, Staniszewska S, Mockford C. The PIRICOM study: a systematic review of the conceptualisation, measurement, impact and outcomes of patients and public involvement in health and social care research, 2010.

50 Maguire K, Britten N. "How can anybody be representative for those kind of people?" Forms of patient representation in health research, and why it is always contestable. Soc Sci Med 2017;183:62-9.

51 Renedo A, Komporozos-Athanasiou A, Marston C. Experience as evidence: the dialogic construction of health professional knowledge through patient involvement. Sociology 2018;52:778-95.

52 Pomey M-P, Ghadiri DP, Karazivan P, et al. Patients as partners: a qualitative study of patients' engagement in their health care. PLoS One 2015;10:e0122499.

53 Greenhalgh T, Papoutsi C. Studying complexity in health services research: desperately seeking an overdue paradigm shift. BMC Med 2018;16:95.

54 Braithwaite J, Churruca K, Long JC, et al. When complexity science meets implementation science: a theoretical and empirical analysis of systems change. BMC Med 2018;16:63.

55 Plsek PE, Wilson T. Complexity, leadership, and management in healthcare organisations. BMJ 2001;323:746-9.

56 Craig P, Dieppe P, Macintyre S, et al. Developing and evaluating complex interventions: the new medical Research Council guidance. BMJ 2008;337:a1655 